\title{
Colonic aberrant crypt formation accompanies an increase of opportunistic pathogenic bacteria in C57BL/6 mice fed a high-fat diet
}

\section{Authors: Huawei Zenga, Suzanne L. Ishaq, Zhenhua Liu, and Michael R. Bukowskia}

NOTICE: this is the author's version of a work that was accepted for publication in Journal of Nutritional Biochemistry Changes resulting from the publishing process, such as peer review, editing, corrections, structural formatting, and other quality control mechanisms may not be reflected in this document. Changes may have been made to this work since it was submitted for publication. A definitive version was subsequently published in Journal of Nutritional Biochemistry, v. 54, April 2018, DOI\#10.1016/j.jnutbio.2017.11.001

Zeng, Huawei, Suzanne L. Ishaq, Zhenhua Liu, and Michael R. Bukowski. "Colonic aberrant crypt formation accompanies an increase of opportunistic pathogenic bacteria in C57BL/6 mice fed a high-fat diet." Journal of Nutritional Biochemistry 54 (April 2018): 18-27. DOI: 10.1016/ j.jnutbio.2017.11.001.

Made available through Montana State University's ScholarWorks scholarworks. montana.edu 


\title{
Colonic aberrant crypt formation accompanies an increase of opportunistic pathogenic bacteria in C57BL/6 mice fed a high-fat diet
}

\author{
Huawei Zeng ${ }^{\mathrm{a}, *}$, Suzanne L Ishaq ${ }^{\mathrm{b}}$, Zhenhua Liu $^{\mathrm{c}}$, Michael R Bukowski ${ }^{\mathrm{a}}$ \\ ${ }^{a}$ United States Department of Agriculture, Agricultural Research Service, Grand Forks Human Nutrition Research Center, Grand Forks, ND 58203 \\ ${ }^{\mathrm{b}}$ Department of Animal and Range Sciences, Montana State University, Bozeman, MT 59717 \\ ${ }^{\mathrm{C} S}$ chool of Public Health and Health Sciences, University of Massachusetts, Amherst, MA 01003
}

\begin{abstract}
The increasing worldwide incidence of colon cancer has been linked to obesity and consumption of a high-fat Western diet. To test the hypothesis that a high-fat diet (HFD) promotes colonic aberrant crypt (AC) formation in a manner associated with gut bacterial dysbiosis, we examined the susceptibility to azoxymethane (AOM)-induced colonic AC and microbiome composition in C57/BL6 mice fed a modified AIN93G diet (AIN, 16\% fat, energy) or an HFD (45\% fat, energy) for 14 weeks. Mice receiving the HFD exhibited increased plasma leptin, body weight, body fat composition and inflammatory cell infiltration in the ileum compared with those in the AIN group. Consistent with the gut inflammatory phenotype, we observed an increase in colonic AC, plasma interleukin-6, tumor necrosis factor- $\alpha$, monocyte chemoattractant protein-1 and inducible nitric oxide synthase in the ileum of the HFD-AOM group compared with the AINAOM group. Although the HFD and AIN groups did not differ in bacterial species number, the HFD and AIN diets resulted in different bacterial community structures in the colon. The abundance of certain short-chain fatty acid (SCFA) producing bacteria (e.g., Barnesiella) and fecal SCFA (e.g., acetic acid) content were lower in the HFD-AOM group compared with the AIN and AIN-AOM groups. Furthermore, we identified a high abundance of Anaeroplasma bacteria, an opportunistic pathogen in the HFD-AOM group. Collectively, we demonstrate that an HFD promotes AC formation concurrent with an increase of opportunistic pathogenic bacteria in the colon of $\mathrm{C} 57 \mathrm{BL} / 6$ mice.
\end{abstract}

Published by Elsevier Inc.

\section{Introduction}

Colon cancer is a major public health issue in the United States, with approximately 137,000 new cases and 50,000 deaths per year [1]. The increasing worldwide incidence of colon cancer has been linked to obesity and consumption of a high-fat (HF) Western diet [2-4]. Metaanalyses indicate that total energy intake is associated with a higher

Abbreviations: AC, aberrant crypt; ACF, aberrant crypt foci; AIN, a modified AIN93G formulation; AOM, azoxymethane; CRP, C-reactive protein; CYP2E1, cytochrome P450 2 E1; HF, high fat; HFD, high-fat diet; IL-6, interleukin-6; iNOS, inducible nitric oxide synthase; LPS, lipopolysaccharide; MCP-1, monocyte chemoattractant protein-1; PBS, phosphate-buffered saline; SCFA, short-chain fatty acid; TNF- $\alpha$, tumor necrosis factor- $\alpha$.

Author disclosures: no conflicts of interest.

This work was funded by the US Department of Agriculture, Agricultural Research Service, Research Projection 3062-51000-050-00D.

Mention of a trademark or proprietary product does not constitute a guarantee or warranty of the product by the U.S. Department of Agriculture and does not imply its approval to the exclusion of other products that may also be suitable.

* Corresponding author at: USDA, ARS, GFHNRC, Grand Forks, ND 58203. Tel.: +1 701795 8465; fax: +1 7017958230 .

E-mail address: huawei.zeng@ars.usda.gov (H. Zeng). risk of colon cancer $[5,6]$. The prevalence of obesity has increased drastically in the Western world as well as the regions where obesity was previously thought to be uncommon (e.g., China, South Korea) during recent decades [3-6]. This global obesity epidemic has, in part, been attributed to the adoption of Western lifestyle, including increased consumption of a high-energy diet such as the high-fat diet (HFD) [5-7].

There is strong epidemiologic evidence linking diet-induced obesity with increased risk of colon cancer [5-8]. Mechanistically, consumption of an HFD can lead to accumulation of excess body fat that is associated with adipose tissue dysfunction and a chronic state of low-grade inflammation known to promote tumor development $[9,10]$. Studies in which germ-free mice inoculated with stool from tumor-bearing mice developed more tumors than those inoculated with stool from tumor-free mice support a causal role for the gut microbiota in colon carcinogenesis in an azoxymethane (AOM)induced colon cancer model [11]. A link between the gut microbiome and colon cancer is increasingly apparent, and an altered microbiota is found among individuals with colon cancer [12,13]. For example, the Clostridium, Roseburia and Eubacterium spp. are less prevalent in colon cancer subjects than in healthy individuals [14]. In addition, some strains of Bacteroides fragilis and Escherichia coli are enterotoxigenic and directly promote tumorigenesis $[11,15]$. 
The symbiotic relationship of hundreds of microbial species with the host requires a tuned response to prevent host damage, e.g., inflammation, while supporting the presence of the potentially beneficial microbes. The colonic microbiota is critical for mucosal tolerance under normal conditions and prevents pathogen infections $[16,17]$. Recent studies show that immunological processes participate in the maintenance of homeostasis with the microbiota and that disturbance of host immunity or the microbial ecosystem results in disease-provoking dysbiosis $[16,17]$. The gastrointestinal tract is poised in a state of equilibrium that permits rapid protective responses against pathogens, but curtails damage by hindering long-lasting vigorous inflammatory processes [18]. While the pathways active in promoting obesity-related colon cancer remain to be characterized, it is possible that the process may involve the colonic microbiota, which affects gut inflammatory status and the extraction of energy from the diet [19-21]. It is known that dietary fiber type, fat composition, composition of gut microbiome/metabolites, animal species and experimental time point are the major factors contributing to the development of inflammation and colon cancer. However, there are few comprehensive studies including all above factors in the context of HFD-induced obesity. It remains largely unknown how colonic aberrant crypt (AC, putative preneoplastic lesions) formation affects gut microbiome/metabolite composition.

We hypothesize that not only does an HFD promote AC formation but obesity and $\mathrm{AC}$ formation are associated with bacterial dysbiosis in the colon. With a comprehensive manner, we tested this hypothesis using the HFD-induced obesity in an AOM mouse model.

\section{Materials and methods}

\subsection{Animals, diets, AOM treatment and AC analysis}

This study was approved by the Animal Care and Use Committee of the Grand Forks Human Nutrition Research Center (GFHNRC), and animals were maintained in accordance with NIH guidelines for the care and use of laboratory animals. Male C57BL/6 mice, 4 weeks old, were obtained from Harlan (Madison, WI, USA). Mice were individually housed in Plexiglas ventilated cages within a pathogen-free facility that maintained a 12-h light/dark cycle. Mice were given free access to food and deionized water and were allowed to acclimate in the facility for 2 days before being randomly assigned to two dietary treatment groups for 14 weeks. A modified AIN93G formulation [22] providing $16 \%$ (AIN, as a control) or $45 \%$ (HFD) of energy from corn oil was prepared by the GFHNRC (Table 1 ) $[23,24]$. C57BL/6 mice were fed either an AIN or HFD ( $n=25$ / group). On week 3 , within a given diet group, mice received either weekly intraperitoneal injection of the colon carcinogen AOM (Sigma, St. Louis, MO, USA) ( $n=15 /$ group) at a concentration of $8 \mathrm{mg} / \mathrm{kg}$ body weight [25] or phosphate-buffered saline (PBS, $\mathrm{pH}=7.4$ ) carrier solution $(n=10$ /group) for 4 weeks. Body weight was recorded weekly, and body composition was measured by magnetic resonance imaging (EchoMRI, Houston, TX, USA) at week 2 and week 14. At the termination of the

Table 1

Composition of experimental diets

\begin{tabular}{|c|c|c|c|c|}
\hline \multirow[t]{2}{*}{ Ingredient } & \multicolumn{2}{|l|}{ AIN } & \multicolumn{2}{|l|}{ HFD } \\
\hline & $\mathrm{g}$ & cal & $\mathrm{g}$ & cal \\
\hline Corn starch & 397.49 & 1589.9 & 33.6 & 134.4 \\
\hline HP casein & 200 & 800 & 200 & 800 \\
\hline Dyetrose & 132 & 400 & 200 & 800 \\
\hline Sucrose & 100 & 528 & 100 & 400 \\
\hline Corn oil & 70 & 630 & 201.5 & 1813.5 \\
\hline Cellulose & 50 & & 50 & \\
\hline Mineral mix AIN93 Dyets & 35 & 30.8 & 35 & 30.8 \\
\hline Vitamin mix AIN93 Tek & 10 & 38.8 & 10 & 38.8 \\
\hline L-Cystine & 3 & 12 & 3 & 12 \\
\hline Choline bitartrate & 2.5 & & 2.4 & \\
\hline TBHQ & 0.014 & & 0.014 & \\
\hline Total (g) and (cal) & 1000 & 4030 & 835.61 & 4030 \\
\hline Energy & $\%$ & & $\%$ & \\
\hline Protein & 20 & & 20 & \\
\hline Fat & 16 & & 45 & \\
\hline Carbohydrate & 64 & & 35 & \\
\hline Energy, cal/kg & 4030 & & 4823.38 & \\
\hline
\end{tabular}

experiment, mice were fasted for $6 \mathrm{~h}$ and then euthanized with a mixture of ketamine and xylazine (100 $\mathrm{mg} / \mathrm{kg}$ body weight). Plasma samples were collected and stored at $80^{\circ} \mathrm{C}$ for analyses of leptin, interleukin-6 (IL6), tumor necrosis factor-alpha (TNF $\alpha$ ), Creactive protein (CRP), monocyte chemoattractant protein-1 (MCP1) and lipopolysaccharide (LPS).

AC and AC foci (ACF) were determined as previously described [26]. Briefly, the entire colon segment and rectum were flushed with PBS solution. Subsequently, the colon and rectum were cut open along the longitudinal median axis and fixed flat on a microscope slide. The fixed colon segments were stained with $0.05 \%$ methylene blue. With methylene blue staining, AC was larger and had a thicker blue lining of epithelial cells than normal crypt; ACF was a darker blue cluster containing one or several ACs. The total number of $\mathrm{AC}$ and $\mathrm{ACF}$ was scored in a blinded manner by using a dissecting microscope to visualize AC/ACF in the entire colon segment which includes ascending, transverse and descending regions.

\subsection{Plasma leptin, IL6, TNF $\alpha$, CRP, MCP-1 and LPS}

The leptin, IL6, TNF $\alpha$ and MCP-1 concentrations were measured in plasma using enzyme-linked immunosorbent assay kits (R\&D Systems, Inc., Minneapolis, MN, USA). Plasma CRP and LPS were assessed by using a CRP (Mouse) assay kit (ANPCO Diagnostics, Salem, NH, USA) and LAL Endotoxin detection Kit (GenScript USA Inc., Piscataway, NJ, USA).

\subsection{Ileum histology, iNOS and Ki67 immunohistochemistry}

Because the colon segment (after AC/ACF analysis) was not suitable for the study of histological end points, we then chose the end region of the ileum segment (a region immediately upstream of the colon). Ileum segments were fixed in $10 \%$ neutral buffered formalin and embedded in paraffin. Five-micrometer sections were mounted on slides and stained with hematoxylin and eosin. Rabbit polyclonal iNOS (cat. \#Ab15323) and Ki67 (cat. \#Ab16667) antibodies (Abcam Inc., Cambridge, MA, USA) were diluted 1:100. The iNOS and Ki67 protein levels were assessed using an immunohistochemistry detection kit including a biotinylated goat anti-rabbit antibody (cat. \#Ab64261) with 1:200 dilution (Abcam Inc., Cambridge, MA, USA). Each ileum section was scored for the area of infiltration of inflammatory cells, iNOS, Ki67 and their respective total section area $\left(\mu \mathrm{m}^{2}\right)$ using a standardized determination of morphology $[27,28]$. The target areas were captured using a Nikon Ci-L Microscope and Leica DFC420 C digital camera. Image Pro Plus Version 9.1 software (Media Cybernetics, Inc., Rockville, MD, USA) was used for quantification of digitized images.

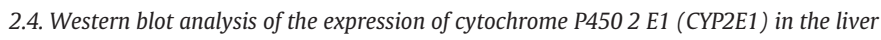

Cell lysates were made by sonicating homogenized liver tissues at $4^{\circ} \mathrm{C}$ using a tissue lysis buffer (Cell Signaling Technologies, Inc., Danvers, MA, USA) as previously described [29]. The protein concentration was quantified by the Bradford dye-binding assay (BioRad Laboratories, Hercules, CA, USA). Equal amounts of protein extract ( $40 \mu \mathrm{g})$ samples were resolved over $4 \%-20 \%$ Tris-glycine gradient gels under denaturing and reducing conditions and electroblotted onto polyvinylidene fluoride membranes (Invitrogen, Carlsbad, CA, USA). Membrane blots were blocked in PBS containing 0.05\% Tween (v:v) supplemented with $1 \%$ (wt:v) nonfat dry milk (BioRad, Hercules, CA, USA) at $4^{\circ} \mathrm{C}$ for overnight. Membranes were probed with antibodies (1:3000 dilution) against CYP2E1 (cat. \#28146) (Abcam, Inc., Cambridge, MA, USA) and then incubated with an antirabbit (1:5000 dilution) HRP-conjugated secondary antibody (cat. \#7074) (Cell Signaling Technology, Inc., Danvers, MA, USA) in blocking solution for $1 \mathrm{~h}$ at room temperature. Blots were washed as above, and proteins were detected by using an enzymatic chemiluminescence plus kit (Amersham Pharmacia Biotech Inc., Piscataway, NJ, USA) with the Molecular Dynamics Image-Quant system (Amersham Pharmacia Biotech Inc., Piscataway, NJ, USA).

2.5. Detection and quantitation of bacterial composition in fecal samples and 165 sequencing

Fecal pellets were collected from each mouse prior to sacrifice at the end of the study and stored at $-80^{\circ} \mathrm{C}$. DNA was extracted from mouse fecal samples using a QIAamp DNA stool Mini Kit (Qiagen, Valencia, CA, USA). DNA was quantified using a Nanodrop Spectrophotometer. The $16 \mathrm{~S}$ universal Eubacterial primers $341 \mathrm{~F}$ CCTACGGGNGGCWGCAG and 785R GACTACHVGGGTATCTAATCC were utilized to generate amplicon products from different samples. A single-step 30-cycle PCR using HotStarTaq Plus Master Mix Kit (Qiagen, Valencia, CA) was used under the following conditions: $94^{\circ} \mathrm{C}$ for 3 min, followed by 28 cycles of $94^{\circ} \mathrm{C}$ for $30 \mathrm{~s} ; 53^{\circ} \mathrm{C}$ for $40 \mathrm{~s}$ and $72{ }^{\circ} \mathrm{C}$ for $1 \mathrm{~min}$; after which a final elongation step at $72^{\circ} \mathrm{C}$ for 5 min was performed [30]. Following polymerase chain reaction (PCR), all amplicon products from different samples were mixed in equal concentrations and purified using Agencourt Ampure beads (Agencourt Bioscience Corporation, Beverly, MA, USA), and samples were sequenced in Molecular Research LP using Illumina MiSeq chemistry platform. Sequencing data are provided through NCBI under BioProject accession \#PRJNA351257. 
A
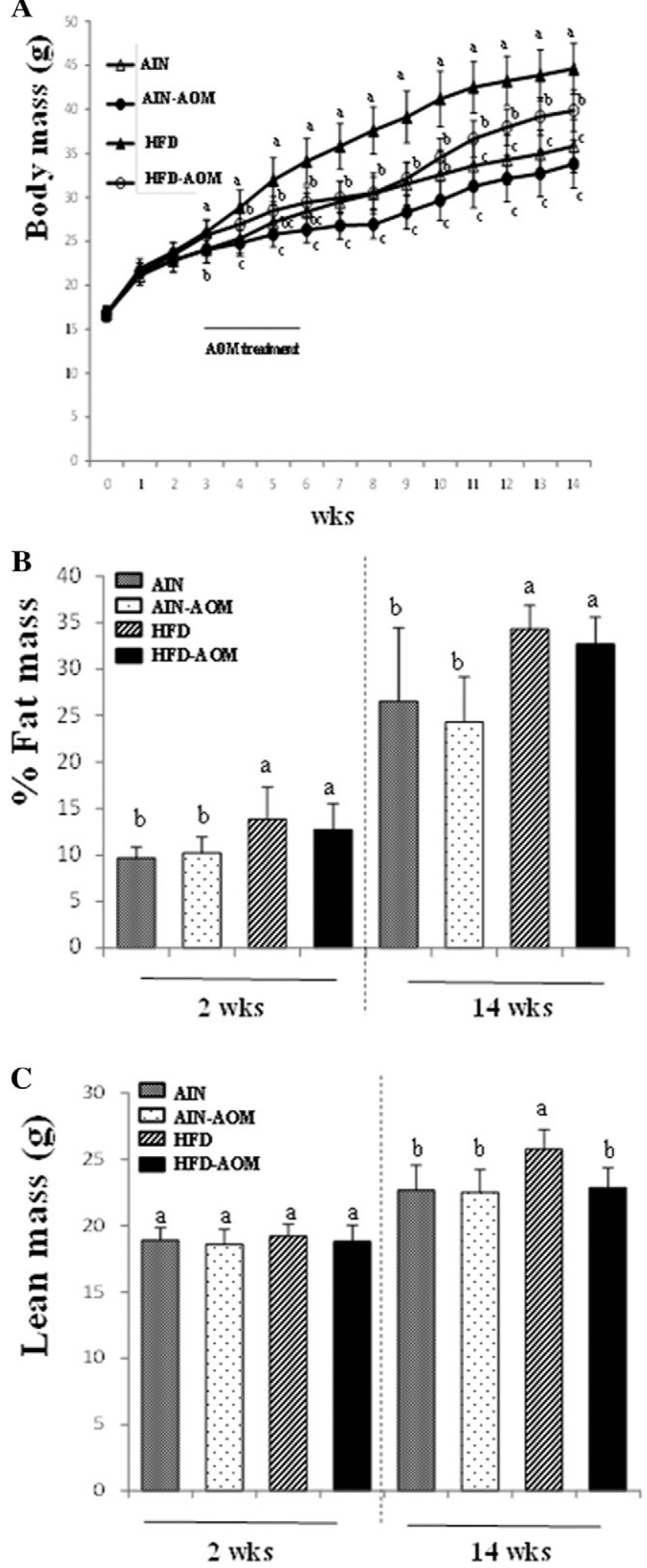

Fig. 1. The effect of HF feeding and AOM treatment on (A) body weight gain ( $g$ ), (B) \% body fat mass and (C) body lean mass (g). Values are means \pm S.D., $n=10 /$ group (AIN, HFD groups) and $n=15 /$ group (AIN-AOM, HFD-AOM groups). At a given time, if two bars share at least one letter, then the difference between them is not statistically significant. However, if they do not have a letter in common, then the difference between them is statistically significant, $P<.05$.
Table 2

Effect of HF feeding and AOM treatment on plasma cytokines

\begin{tabular}{lcccc}
\hline & AIN & AIN-AOM & HFD & HFD-AOM \\
\hline Plasma TNF $\alpha, \mathrm{pg} / \mathrm{ml}$ & $1.7 \pm 0.69^{\mathrm{b}}$ & $2.4 \pm 0.99^{\mathrm{b}}$ & $2.2 \pm 0.81^{\mathrm{b}}$ & $5.1 \pm 1.73^{\mathrm{a}}$ \\
Plasma leptin, ng/ml & $19.4 \pm 6.97^{\mathrm{b}}$ & $16.1 \pm 10.51^{\mathrm{b}}$ & $47.7 \pm 10.03^{\mathrm{a}}$ & $44.5 \pm 10.83^{\mathrm{a}}$ \\
Plasma IL6, pg/ml & $1.9 \pm 0.52^{\mathrm{b}}$ & $2.7 \pm 1.40^{\mathrm{b}}$ & $1.9 \pm 0.95^{\mathrm{b}}$ & $5.2 \pm 2.36^{\mathrm{a}}$ \\
Plasma CRP, ng/ml & $0.6 \pm 0.12$ & $0.5 \pm 0.04$ & $0.5 \pm 0.04$ & $0.6 \pm 0.06$ \\
Plasma MCP-1, pg/ml & $23.7 \pm 5.12^{\mathrm{b}}$ & $56.4 \pm 29.13^{\mathrm{b}}$ & $34.5 \pm 8.95^{\mathrm{b}}$ & $112.2 \pm 46.79^{\mathrm{a}}$ \\
Plasma LPS, EU/10 ml & $0.61 \pm 0.26^{\mathrm{b}}$ & $0.76 \pm 0.29^{\mathrm{ab}}$ & $0.84 \pm 0.31^{\mathrm{ab}}$ & $0.95 \pm 0.18^{\mathrm{a}}$ \\
\hline
\end{tabular}

Values are means \pm S.D., $n=9$ to 10 /group (AIN, HFD groups) and $n=13$ to 15 /group (AIN-AOM, HFD-AOM group). Means at the same cytokine without a common letter differ, $P<.05$.

\subsection{Fecal short-chain fatty acid (SCFA) analysis}

Fecal pellets were collected from each mouse prior to sacrifice at the end of the study and stored at $-80^{\circ} \mathrm{C}$. Pulverized mouse fecal samples $(25 \mathrm{mg}$ ) were suspended in $1 \mathrm{ml}$ water, acidified with $54 \mu \mathrm{l} 6 \mathrm{M} \mathrm{HCl}$ and spiked with ethyl-butyric acid as an internal standard in the analyzed solution $(0.26 \mathrm{mmol} / \mathrm{L})$. Samples were homogenized by a TissueLyser (Qiagen, Valencia, CA, USA) and then kept on ice for $15 \mathrm{~min}$ with intermittent vortexing. The samples were centrifuged at $17,000 \times \mathrm{g}$ for $20 \mathrm{~min}$ at $4^{\circ} \mathrm{C}$, and the supernatant was collected. The SCFA composition was measured by gas chromatography using a Thermo Trace-1310 equipped with a TriPlus RSH Autosampler (Thermo Fisher, Waltham, MA, USA) and a fatty acid phase column (DB-FFAP 125-3237, J\&W Scientific, Agilent Technologies Inc., Santa Clara, CA, USA) as previously described [31]

\subsection{Statistical analysis}

Results are given as mean \pm standard deviation (S.D.). The effects of diet (AIN or HFD) and AOM treatment (with or without) on mouse body weight, body composition, inflammatory cytokines and immunohistochemistry variables were analyzed using a two-way analysis of variance and Tukey's contrasts for post hoc comparisons. JMP V12 (SAS Institute Inc., Cary, NC, USA) was used for all statistical analyses. To analyze the DNA sequencing data and various microbiome measures, statistical analysis was performed using a variety of computer packages including the open-source computer software QIIME/MOTHUR ver. 1.38 program (SAS Institute Inc., Cary, NC, USA) [32,33]. The number of operational taxonomic units (OTUs) and weighted UniFrac distance matrices were used to evaluate the number of species (alpha diversity) and bacterial community structure in different groups, respectively. These diversity analyses were conducted as previously described [30,34-36] using OIIME (www.qiime.org). The significance of microbial percentage abundance between groups, defined as having a threshold $>0.28 \%$ in at least one treatment group, was determined by XLstat NCSS 2010 and $\mathrm{R}$ language using multivariate analysis of variance coupled with Tukey's honestly significant difference to adjust $P$ values. A correlogram was created in $\mathrm{R}$ (corrplot language) using Pearson rank correlations of abundance data for Anaeroplamsa and Lactobacillus at the genus and individual species levels. Differences with a $P$ value $<.05$ were considered statistically significant.

\section{Results}

3.1. Effects of the HFD and AOM treatment on daily food consumption, body mass and body fat composition

The average daily food intakes in the AIN and AIN-AOM groups were greater $(P<.05)$ than that of the HFD and HFD-AOM groups $(3.93 \pm 0.14 \mathrm{~g}, 3.95 \pm 0.16 \mathrm{~g}$ vs $3.30 \pm 0.15 \mathrm{~g}, 3.28 \pm 0.19 \mathrm{~g})$, respectively. However, the energy intakes (calories/day) in the AIN and AIN-AOM, HFD and HFD-AOM groups did not differ $(15.85 \pm 0.58$, $15.93 \pm 0.65,15.94 \pm 0.72,15.84 \pm 0.0 .93$ ), respectively. The AOM treatment did not change the food intake within a given diet. The HFD consumption increased body mass when compared to AIN groups 3 weeks after initiation of experimental feeding (Fig. 1A). Although the AOM treatment decreased the rate of body mass weight gain compared to the respective untreated groups, the AIN-AOM and HFD-AOM groups experienced body mass weight gain over the entire experiment (Fig. 1A). Regardless of the AOM treatment, the HFD group increased the percent body fat mass by 0.32 -fold compared with the AIN group (Fig. 1B); however, the absolute lean mass weight in the HFD group was greater than in the HFD-AOM, AIN and AINAOM groups at the end of experiment (Fig. 1C). 


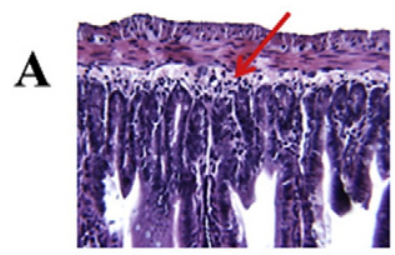

Immuno-cells $\quad 0.36 \pm 0.31^{\mathrm{b}} \%$
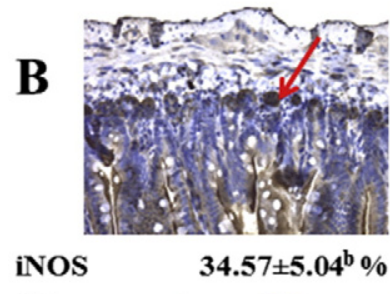

C

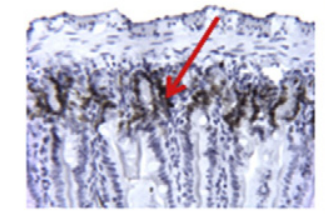

Ki67

$10.12 \pm 2.92^{\mathrm{b}} \%$

$\underline{\text { AIN }}$

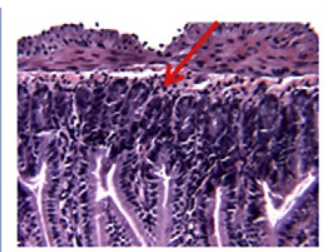

$0.39 \pm 0.14^{\mathrm{b}} \%$

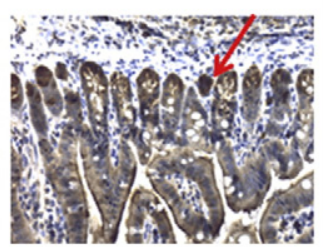

$40.13 \pm 8.60^{b} \%$

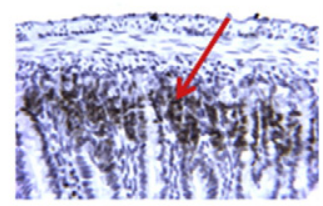

$12.15 \pm 3.38^{b} \%$

$\underline{\text { AIN-AOM }}$

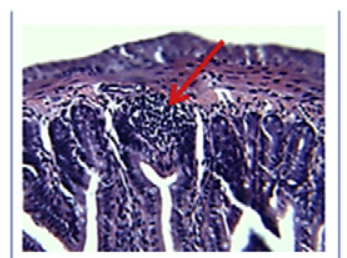

$0.95 \pm 0.35^{\mathrm{a}} \%$

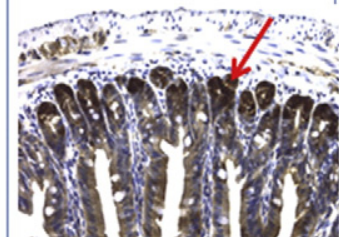

$39.18 \pm 7.78^{\mathrm{b}} \%$

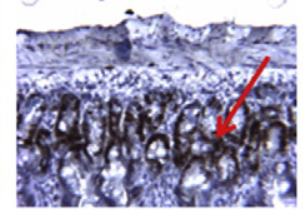

$17.27 \pm 2.68^{\mathrm{ab}} \%$

HFD

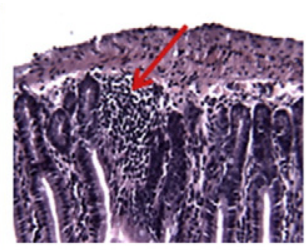

$1.06 \pm 0.30^{\mathrm{a}} \%$

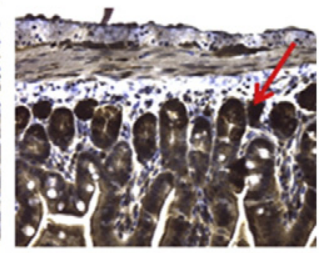

$48.86 \pm 9.60^{\mathrm{a}} \%$

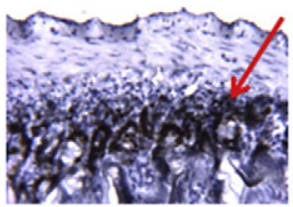

$21.43 \pm 4.16^{\mathrm{a}} \%$

HFD-AOM

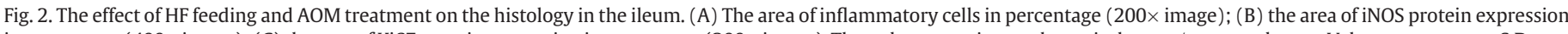

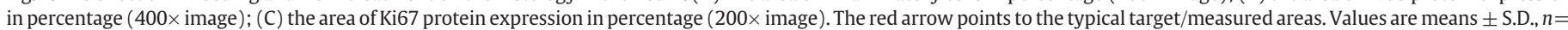

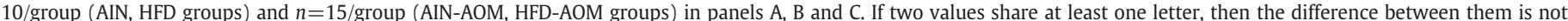
statistically significant. However, if they do not have a letter in common, then the difference between them is statistically significant, $P<.05$.

3.2. Effects of the HFD and AOM treatment on plasma inflammatory cytokines and LPS

The concentrations of plasma leptin in the HFD and HFD-AOM group were 1.45 - and 1.77 -fold greater than in the AIN and AIN-AOM groups, respectively. Furthermore, the concentrations of plasma TNF $\alpha$, IL 6 and MCP-1 were at least 1-fold greater in the HFD-AOM group than in the AIN, AIN-AOM and HFD groups; similarly, the concentration of plasma LPS was 0.5 -fold greater in the HFD-AOM group than in the AIN group. However, the concentrations of plasma CRP did not differ between groups (Table 2).
A

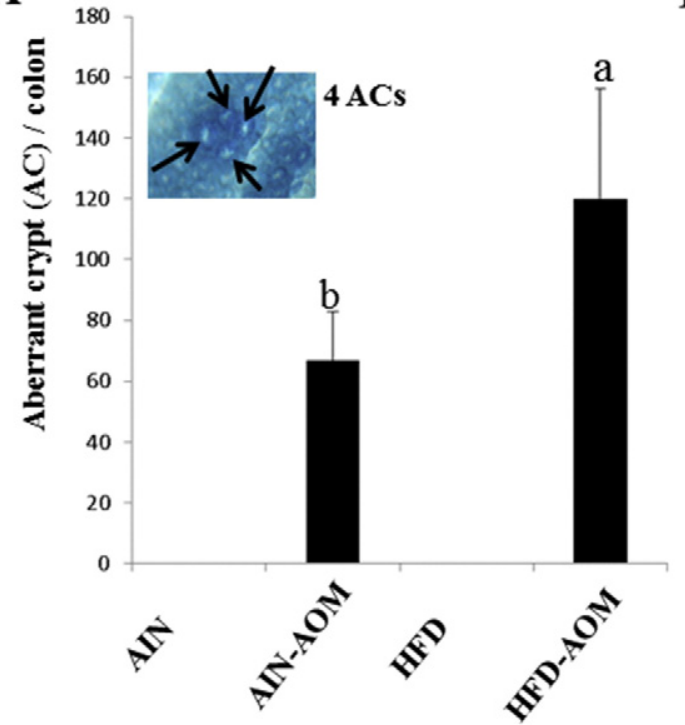

B

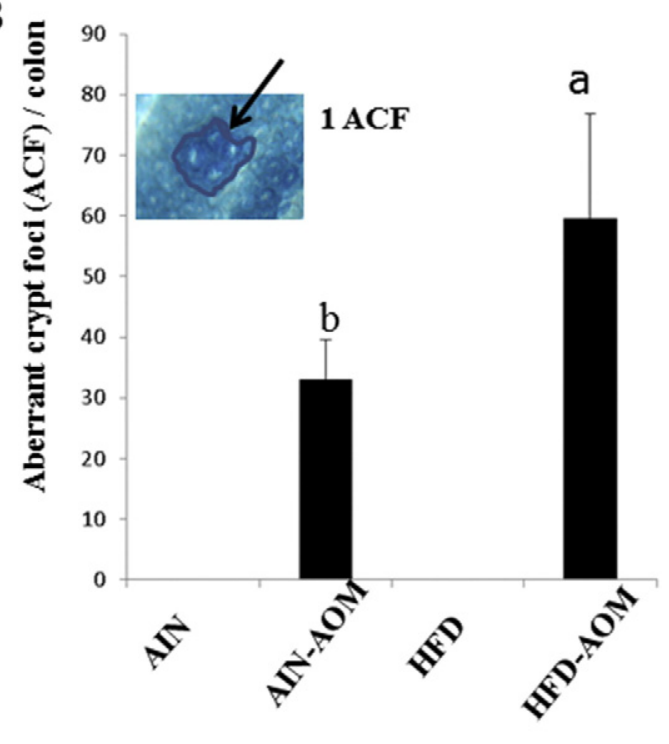

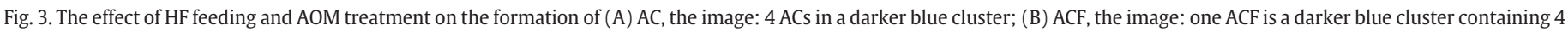

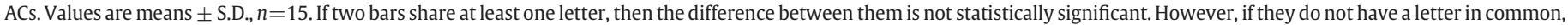
then the difference between them is statistically significant, $P<.05$. *PBS treatment ( $n=10 /$ group) (AIN, HFD groups) did not develop AC/ACF. 
P450 2E1

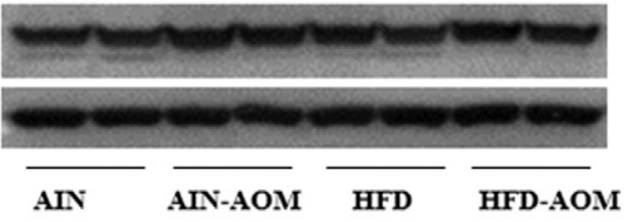

GAPDH

Density units

$\begin{array}{lllll}\text { P450 2E1 } & 5494 \pm 394^{\mathrm{a}} & 4975 \pm 571^{\mathrm{a}} & 5514 \pm 982^{\mathrm{a}} & 5092 \pm 576^{\mathrm{a}} \\ \text { GAPDH } & 5605 \pm 323^{\mathrm{a}} & 5388 \pm 802^{\mathrm{a}} & 5320 \pm 640^{\mathrm{a}} & 5691 \pm 416^{\mathrm{a}} \\ & & & & \\ \text { Ratio } & & & & \\ \text { P450 2E1 } & 0.98 \pm 0.11^{\mathrm{a}} & 0.94 \pm 0.14^{\mathrm{a}} & 1.05 \pm 0.24^{\mathrm{a}} & 0.89 \pm 0.07^{\mathrm{a}} \\ \text { / GAPDH } & & & & \end{array}$

Fig. 4. The effect of HF feeding and AOM treatment on the hepatic P450 2E1 protein level. Values are means \pm S.D., $n=8$ /group. If two values share at least one letter, then the difference between them is not statistically significant. However, if they do not have a letter in common, then the difference between them is statistically significant, $P<.05$.

3.3. Effects of the HFD and AOM treatment on inflammatory cell infiltration, iNOS and Ki67 protein level in ileum

At the end of the experiment, histological examination of ileum sections showed that the areas of inflammatory cells in the HFD and HFD-AOM groups were 1.64- to 1.72-fold greater than in the AIN and AIN-AOM groups (Fig. 2A). The level of the proinflammatory cytokine regulator iNOS protein in the HFD-AOM group was 0.41-, 0.22- and 0.25 -fold greater than in the AIN, AIN-AOM, HFD groups (Fig. 2B), respectively. The level of cell proliferation marker Ki67 protein in the HFD-AOM groups was 1.12- and 0.76-fold greater than in the AIN and AIN-AOM groups (Fig. 2C), respectively.

\subsection{Effects of the HFD on AC/ACF formation}

The number of AC and ACF in the HFD-AOM group was 0.80 - and 0.81 -fold greater than in the AIN-AOM group, respectively. The AIN and HFD groups did not develop AC and ACF (Fig. 3A and B).

3.5. Effects of the HFD and AOM treatment on hepatic P450 2E1 protein level

The levels of hepatic CYP2E1 protein, the major AOM bioactivation enzyme [37], did not differ in the AIN, AIN-AOM, HFD and HFD-AOM groups (Fig. 4).

\subsection{Effects of the HFD on gut microbial diversity and composition}

The OTUs at the species level and the Shannon diversity index were used to determine the diversity of bacterial species within a treatment group. Although the AIN and HFD groups did not differ, the HFD-AOM group had a higher bacterial diversity when compared to that of AINAOM group (Table 3). In contrast, there was a significant difference in the bacterial community structure based on diet but not AOM treatment (Fig. 5). At the phylum level, the HFD-AOM group increased the abundance of Proteobacteria but decreased the abundance of Actinobacteria when compared with the AIN-AOM group. Similarly, the HFD-AOM group had higher abundance of Tenericutes bacteria than in the HFD group (Fig. 6). With an abundance threshold of $>0.28 \%$ total bacteria in at least one experimental group, we identified significant changes in 21 genera, 10 families, 4 orders, 4 classes and 3 phyla due to differences in diet, AOM treatments or both (Fig. 6, Tables 3 and 4). At genus level, three major (high abundance) bacterial taxa (Bacteroides, Barnesiella, Lachnoclostridium), which are responsible for SCFA production [38-41], were at least 1-fold higher in the AIN group when compared with the HFD group (Table 3). We also found that the abundance of Anaeroplasma (an opportunistic pathogen) and

Table 3

Effect of HF feeding and AOM treatment on taxonomic unit counts of gut bacteria and mean percentage abundance of each genus detected within each group

\begin{tabular}{|c|c|c|c|c|}
\hline & AIN & AIN-AOM & HFD & HFD-AOM \\
\hline \multicolumn{5}{|l|}{ Taxonomic unit counts } \\
\hline Observed species & $945.4 \pm 89.6^{\mathrm{a}}$ & $929.2 \pm 107.9^{a}$ & $993.0 \pm 123.1^{\mathrm{ab}}$ & $1082.6 \pm 120.3^{\mathrm{b}}$ \\
\hline Shannon index & $5.62 \pm 0.51^{\mathrm{ab}}$ & $5.21 \pm 0.66^{\mathrm{a}}$ & $5.47 \pm 0.59^{\mathrm{ab}}$ & $5.92 \pm 0.38^{\mathrm{b}}$ \\
\hline \multicolumn{5}{|l|}{ Percentage abundance } \\
\hline Bifidobacterium & $16.19 \pm 11.64^{\mathrm{ab}}$ & $26.44 \pm 13.83^{\mathrm{a}}$ & $21.56 \pm 12.83^{\mathrm{ab}}$ & $12.17 \pm 8.47^{\mathrm{b}}$ \\
\hline Bacteroides & $17.44 \pm 3.93^{\mathrm{a}}$ & $12.66 \pm 7.14^{\mathrm{ab}}$ & $9.26 \pm 2.62^{\mathrm{b}}$ & $9.07 \pm 3.05^{\mathrm{b}}$ \\
\hline Rikenella & $4.93 \pm 2.06^{\mathrm{b}}$ & $5.31 \pm 1.96^{\mathrm{b}}$ & $6.40 \pm 1.74^{\mathrm{b}}$ & $9.92 \pm 3.91^{\mathrm{a}}$ \\
\hline Barnesiella & $9.85 \pm 1.56^{\mathrm{a}}$ & $8.50 \pm 2.73^{\mathrm{a}}$ & $3.65 \pm 1.93^{\mathrm{b}}$ & $4.60 \pm 1.26^{\mathrm{b}}$ \\
\hline Lactococcus & $4.36 \pm 1.35^{\mathrm{b}}$ & $5.01 \pm 2.03^{b}$ & $10.12 \pm 3.45^{\mathrm{a}}$ & $6.63 \pm 4.63^{\mathrm{ab}}$ \\
\hline Alistipes & $3.44 \pm 1.44^{\mathrm{b}}$ & $2.11 \pm 0.86^{\mathrm{b}}$ & $9.35 \pm 3.29^{a}$ & $7.37 \pm 2.14^{a}$ \\
\hline Lachnoclostridium & $6.03 \pm 2.78^{a}$ & $5.80 \pm 2.55^{\mathrm{a}}$ & $3.14 \pm 1.25^{\mathrm{b}}$ & $4.58 \pm 1.92^{\mathrm{ab}}$ \\
\hline Acetivibrio & $1.28 \pm 0.73^{\mathrm{b}}$ & $1.35 \pm 0.98^{\mathrm{b}}$ & $3.17 \pm 1.39^{a}$ & $3.10 \pm 1.78^{\mathrm{a}}$ \\
\hline Oscillospira & $1.61 \pm 0.59^{b}$ & $1.61 \pm 0.73^{\mathrm{b}}$ & $2.63 \pm 0.77^{\mathrm{a}}$ & $2.80 \pm 0.92^{\mathrm{a}}$ \\
\hline Lactobacillus & $0.06 \pm 0.11^{\mathrm{b}}$ & $0.84 \pm 1.65^{\mathrm{ab}}$ & $0.18 \pm 0.22^{\mathrm{b}}$ & $3.32 \pm 4.56^{\mathrm{a}}$ \\
\hline Robinsoniella & $1.78 \pm 1.09^{\mathrm{a}}$ & $1.85 \pm 1.01^{\mathrm{a}}$ & $0.46 \pm 0.12^{\mathrm{b}}$ & $0.76 \pm 0.31^{\mathrm{b}}$ \\
\hline Parabacteroides & $1.09 \pm 0.38^{\mathrm{bc}}$ & $0.73 \pm 0.38^{c}$ & $1.49 \pm 0.47^{\mathrm{ab}}$ & $1.63 \pm 0.51^{\mathrm{a}}$ \\
\hline Eubacterium & $1.06 \pm 0.51^{\mathrm{ab}}$ & $0.63 \pm 0.39^{b}$ & $0.85 \pm 0.68^{\mathrm{ab}}$ & $1.34 \pm 0.93^{\mathrm{a}}$ \\
\hline Moryella & $0.61 \pm 0.60^{\mathrm{ab}}$ & $0.47 \pm 0.60^{\mathrm{b}}$ & $0.92 \pm 0.70^{\mathrm{ab}}$ & $1.21 \pm 0.78^{a}$ \\
\hline Roseburia & $0.41 \pm 0.17^{\mathrm{b}}$ & $0.40 \pm 0.17^{\mathrm{b}}$ & $1.22 \pm 0.35^{\mathrm{a}}$ & $1.09 \pm 0.45^{\mathrm{a}}$ \\
\hline Butyricimonas & $0.17 \pm 0.10^{\mathrm{b}}$ & $0.16 \pm 0.10^{b}$ & $1.27 \pm 0.62^{\mathrm{a}}$ & $0.85 \pm 0.62^{\mathrm{a}}$ \\
\hline Hydrogenoanaerobacterium & $0.23 \pm 0.11^{\mathrm{b}}$ & $0.19 \pm 0.11^{\mathrm{b}}$ & $0.45 \pm 0.17^{\mathrm{a}}$ & $0.41 \pm 0.20^{\mathrm{a}}$ \\
\hline Bilophila & $0.28 \pm 0.15^{\mathrm{ab}}$ & $0.23 \pm 0.11^{\mathrm{b}}$ & $0.28 \pm 0.14^{\mathrm{ab}}$ & $0.41 \pm 0.16^{\mathrm{a}}$ \\
\hline Odoribacter & $0.18 \pm 0.09^{b}$ & $0.19 \pm 0.17^{b}$ & $0.22 \pm 0.10^{\mathrm{ab}}$ & $0.44 \pm 0.35^{\mathrm{a}}$ \\
\hline Anaerotruncus & $0.12 \pm 0.06^{\mathrm{b}}$ & $0.14 \pm 0.09^{\mathrm{b}}$ & $0.39 \pm 0.13^{\mathrm{a}}$ & $0.33 \pm 0.15^{\mathrm{a}}$ \\
\hline Anaeroplasma & $0.08 \pm 0.11^{\mathrm{b}}$ & $0.17 \pm 0.17^{\mathrm{ab}}$ & $0.05 \pm 0.05^{\mathrm{b}}$ & $0.30 \pm 0.20^{\mathrm{a}}$ \\
\hline
\end{tabular}

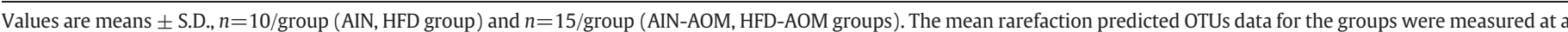
depth of 26,146 sequences. Means at the same genus without a common letter differ, $P<.05$. 


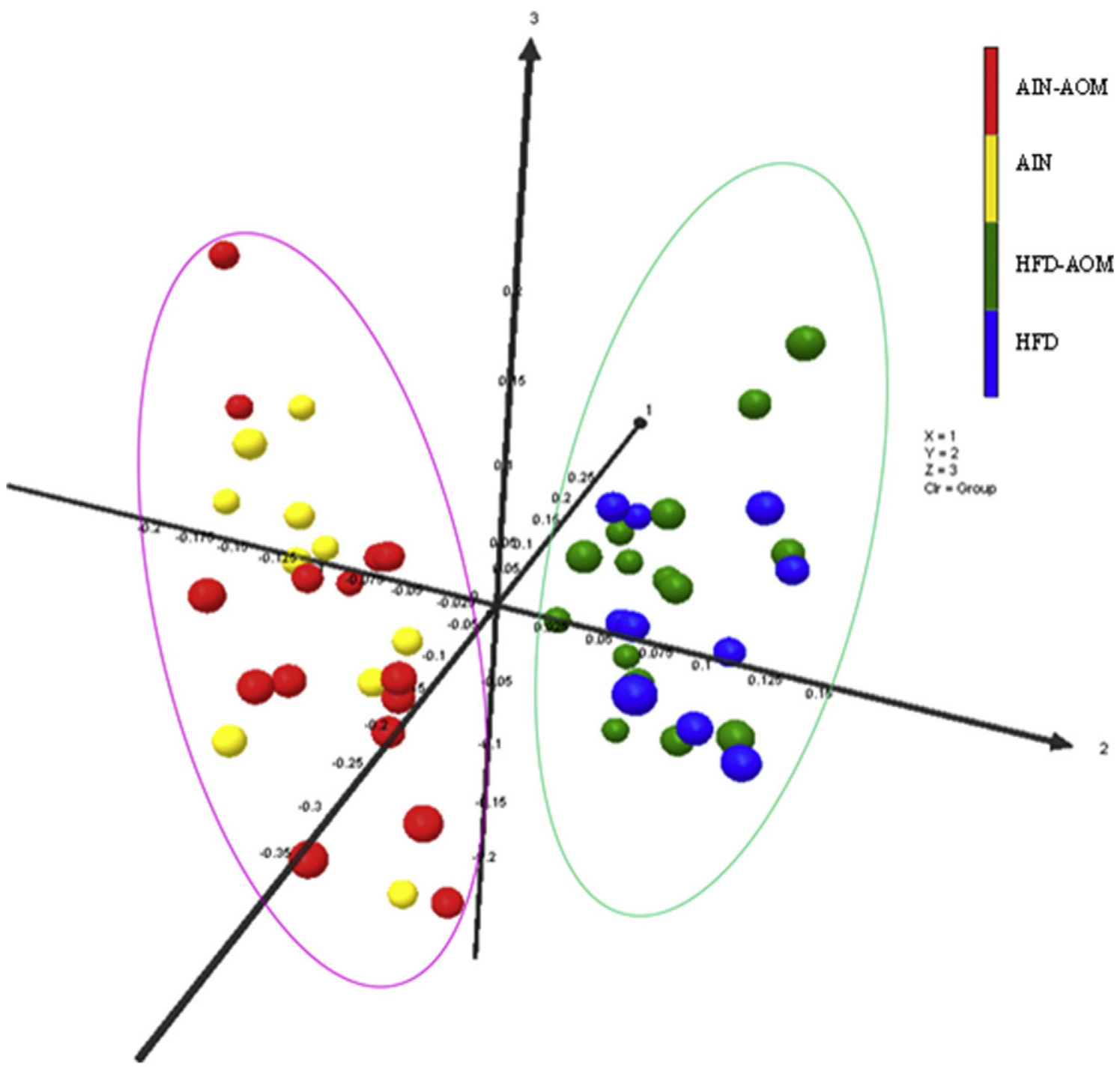

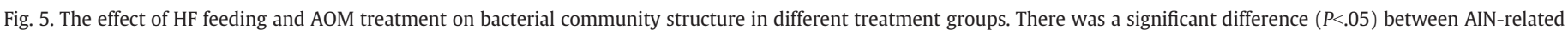
groups vs HFD-related groups.

Lactobacillus bacteria increased 6.6- and 18.1-fold, respectively, in the HFD-AOM group when compared with the HFD group (Table 3 ). Moreover, the analysis indicated that there was a positive relationship of AC/ACF number and the abundance of Anaeroplasma/Lactobacillus bacteria at genus and species levels (Fig. 7).

\subsection{Effects of the HFD on fecal SCFA content}

As we detected a higher abundance of SCFA-producing bacteria in the AIN group when compared with the HFD group, we then determined fecal SCFA content. Due to AOM treatment, the amount of fecal acetic acid was decreased by $30 \%$ in the HFD-AOM group when compared with the AIN and AIN-AOM groups. However, the content of propionic acid and butyric acid did not differ (Fig. 8).

\section{Discussion}

Epidemiological and experimental data suggest that obesity increases colon cancer risk [2,3,6-9]. In the current study, we tested the hypothesis that obesity promotes AC formation with an increase of pathogenic bacteria in the colon using an HFD to produce outcomes similar to those observed adiposity in humans $[9,42,43]$. Our data support this hypothesis and demonstrate involvement of inflammatory processes and changes in the microbiome.

\subsection{The HFD consumption induces obesity}

It is interesting to note that the daily calorie intake did not differ but the HFD group exhibited a significant increase in body weight and fat mass percentage when compared with the AIN group (Fig. 1). This observation is likely due to the nutrient utilization and energy expenditure because laboratory rodents fed energy-rich HF diets (ad lib) exhibit particularly deleterious effects on circadian rhythm, leading to the disruption of metabolic cycle [44,45]. Second, an HFDinduced obesity is mainly due to the fat mass increase; fat as energy source requires fewer biochemical steps to produce the fat mass when compared with that of protein/carbohydrate as energy [44,45]. Third, the germ-free animal studies have shown that the development of a microbiome favored by an HFD promotes energy harvest and storagepromoting obesity and metabolic diseases $[46,47]$. 


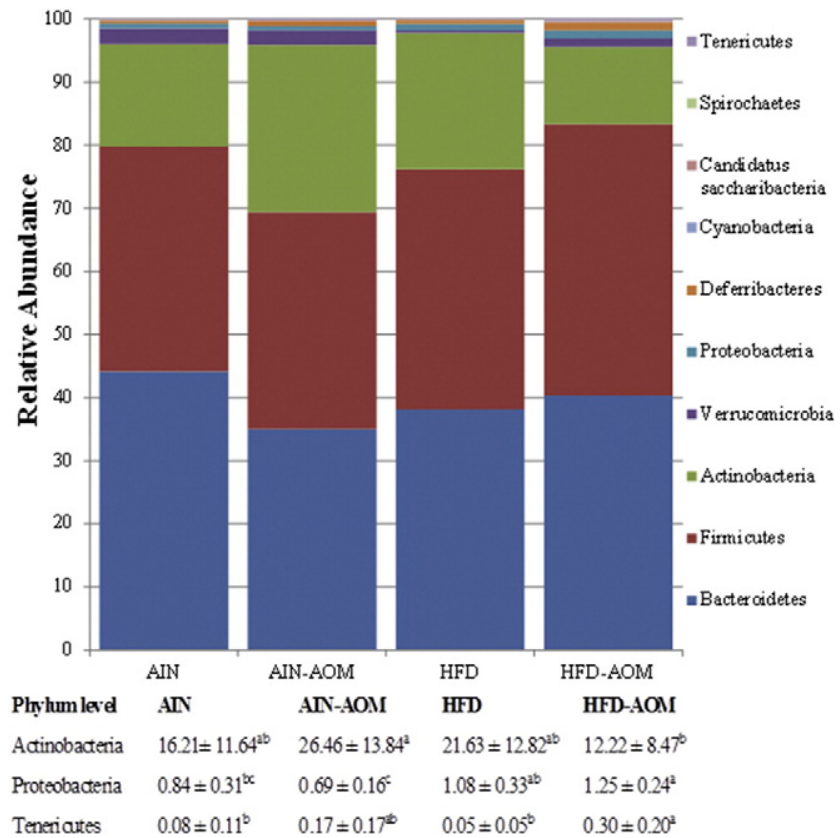

Fig. 6. The effect of HF feeding and AOM treatment on relative abundance of bacterial phyla in different treatment groups. Firmincute, Actinbacteria, Proteobacteria and Tenericutes were the four bacterial phyla with significant changes. Values are means \pm S.D., $n=10 /$ group (AIN, HFD groups) and $n=15 /$ group (AIN-AOM, HFD-AOM groups). If two values share at least one letter in the same taxon, then the difference between them is not statistically significant. However, if they do not have a letter in common, then the difference between them is statistically significant, $P<.05$.

\subsection{The combination of HFD consumption and AOM treatment greatly increases inflammatory responses}

The cytokines serve as messengers between cells and regulate various inflammatory responses. Leptin, TNF- $\alpha$, IL6 and MCP-1 are key obesity-related proinflammatory cytokines $[9,48]$. They are released by inflammatory cells infiltrating adipose tissue and regulate cell survival, apoptosis, migration and macrophage infiltration into adipose tissue $[49,50]$. These proinflammatory cytokines were greatly elevated in the HFD-AOM group compared with other groups (Table 2).

Similarly, we examined the gut inflammation using ileum segment because the entire colon segment was used to determine AC/ACF number. First, in the normal ileum segment, few inflammatory cells can be found in the mucosa next to the basal membrane of the epithelial layer, but at the inflamed tissue, the inflammatory cells are greatly increased in the lamina propria of intestine, and these cells secret proinflammatory cytokines and other related mediators [51,52]. In our study, HF feeding caused an increase of inflammatory cells in ileum segments (Fig. 2A), suggesting that ileum was more inflamed in the HFD and HFD-AOM groups than the AIN and AIN-AOM groups. Second, the regulation of proinflammatory cytokines by iNOS may contribute to the pathogenesis of the inflammatory process, and the expression of iNOS was significantly increased in inflamed tissue [53,54]. Similarly, intestinal inflammation is invariably associated with increased epithelial proliferation. However, in the intestine, it is more difficult to examine changes in cell proliferation, but using cell proliferation gene Ki67, epithelial proliferation has been shown to be increased in inflamed tissue $[55,56]$. Moreover, nitric oxide generated at the inflammatory site contributes to the initiation and progression of colon tumorigenesis by enhancing expression of proinflammatory enzyme iNOS and cell proliferation gene Ki67 [57,58]. Therefore, the hindgut region was more inflamed in the HFD-AOM group than the other groups (Fig. 2B and C) because the region of the ileum we used was located at the immediate upstream of an ascending colon, and it shares the similar inflammatory status with the colon segment. Indeed, we have previously demonstrated that the ileum and colon segments yield similar results on inflammatory cell filtration, iNOS and Ki67 protein levels in response to low- and high-fat diet treatment [59]. Our observation is also consistent with the report that the colonic stem cells of the HF-fed mice exhibited statistically significant increases in cell proliferation and decreases in apoptosis in response to AOM injection compared to the control group [60]. Future studies on the effects of HF feeding on colonic stem cell maintenance, proliferation and molecular signals in a primary organoid model from the AIN- or HFD-fed mice may provide insight into the mechanistic pathways directly related to colonic AC formation [60,61].

Overall, that both the HFD and AOM stimuli were needed suggests synergistic or complementary effects on increasing proinflammatory cytokines and gut inflammation.

Table 4

Effect of HF feeding and AOM treatment on mean percentage abundance of each class, order and family detected within each group

\begin{tabular}{|c|c|c|c|c|}
\hline & AIN & AIN-AOM & HFD & HFD-AOM \\
\hline \multicolumn{5}{|l|}{ Class level } \\
\hline Actinobacteria & $16.21 \pm 11.64^{\mathrm{ab}}$ & $26.46 \pm 13.84^{\mathrm{a}}$ & $21.63 \pm 12.82^{\mathrm{ab}}$ & $12.22 \pm 8.47^{\mathrm{b}}$ \\
\hline Bacilli & $4.93 \pm 1.33^{\mathrm{b}}$ & $6.22 \pm 1.99^{\mathrm{ab}}$ & $10.92 \pm 3.40^{\mathrm{a}}$ & $10.45 \pm 7.24^{\mathrm{a}}$ \\
\hline Deltaproteobacteria & $0.40 \pm 0.19^{b}$ & $0.35 \pm 0.13^{\mathrm{b}}$ & $0.49 \pm 0.19^{\mathrm{ab}}$ & $0.68 \pm 0.24^{\mathrm{a}}$ \\
\hline Mollicutes & $0.08 \pm 0.11^{\mathrm{b}}$ & $0.17 \pm 0.17^{\mathrm{ab}}$ & $0.05 \pm 0.05^{\mathrm{b}}$ & $0.30 \pm 0.20^{\mathrm{a}}$ \\
\hline \multicolumn{5}{|l|}{ Order level } \\
\hline Bifidobacteriales & $16.19 \pm 11.64^{\mathrm{ab}}$ & $26.44 \pm 13.83^{\mathrm{a}}$ & $21.56 \pm 12.83^{\mathrm{ab}}$ & $12.17 \pm 8.47^{\mathrm{b}}$ \\
\hline Lactobacillales & $4.83 \pm 1.34^{\mathrm{b}}$ & $6.13 \pm 1.99^{\mathrm{ab}}$ & $10.81 \pm 3.41^{\mathrm{a}}$ & $10.33 \pm 7.25^{\mathrm{a}}$ \\
\hline Desulfovibrionales & $0.40 \pm 0.19^{b}$ & $0.35 \pm 0.13^{\mathrm{b}}$ & $0.49 \pm 0.19^{\mathrm{ab}}$ & $0.68 \pm 0.24^{\mathrm{a}}$ \\
\hline Anaeroplasmatales & $0.08 \pm 0.11^{\mathrm{b}}$ & $0.17 \pm 0.17^{\mathrm{ab}}$ & $0.05 \pm 0.05^{\mathrm{b}}$ & $0.30 \pm 0.20^{\mathrm{a}}$ \\
\hline \multicolumn{5}{|l|}{ Family level } \\
\hline Bifidobacteriales & $16.19 \pm 11.64^{\mathrm{ab}}$ & $26.44 \pm 13.83^{\mathrm{a}}$ & $21.56 \pm 12.83^{\mathrm{ab}}$ & $12.17 \pm 8.47^{\mathrm{b}}$ \\
\hline Porphyromonadaceae & $18.30 \pm 1.50^{\mathrm{a}}$ & $14.91 \pm 3.81^{\mathrm{ab}}$ & $13.07 \pm 3.77^{\mathrm{b}}$ & $13.92 \pm 2.82^{\mathrm{b}}$ \\
\hline Rikenellaceae & $8.37 \pm 2.80^{\mathrm{b}}$ & $7.42 \pm 2.13^{\mathrm{b}}$ & $15.75 \pm 4.47^{\mathrm{a}}$ & $17.29 \pm 4.97^{\mathrm{a}}$ \\
\hline Bacteroidaceae & $17.44 \pm 3.93^{\mathrm{a}}$ & $12.66 \pm 7.13^{\mathrm{ab}}$ & $9.26 \pm 2.62^{\mathrm{b}}$ & $9.08 \pm 3.05^{\mathrm{b}}$ \\
\hline Streptococcaceae & $4.38 \pm 1.35^{\mathrm{b}}$ & $5.03 \pm 2.04^{\mathrm{b}}$ & $10.13 \pm 3.45^{\mathrm{a}}$ & $6.64 \pm 4.63^{\mathrm{ab}}$ \\
\hline Ruminococcaceae & $3.66 \pm 1.15^{\mathrm{b}}$ & $3.82 \pm 1.58^{\mathrm{b}}$ & $7.26 \pm 2.07^{\mathrm{a}}$ & $8.07 \pm 2.44^{a}$ \\
\hline Lactobacillaceae & $0.06 \pm 0.11^{\mathrm{b}}$ & $0.84 \pm 1.65^{\mathrm{ab}}$ & $0.18 \pm 0.22^{\mathrm{b}}$ & $3.32 \pm 4.56^{\mathrm{a}}$ \\
\hline Eubacteriaceae & $1.06 \pm 0.51^{\mathrm{ab}}$ & $0.63 \pm 0.38^{\mathrm{b}}$ & $0.85 \pm 0.68^{\mathrm{ab}}$ & $1.35 \pm 0.93^{\mathrm{a}}$ \\
\hline Desulfovibrionaceae & $0.40 \pm 0.19^{\mathrm{b}}$ & $0.35 \pm 0.13^{\mathrm{b}}$ & $0.49 \pm 0.19^{\mathrm{ab}}$ & $0.68 \pm 0.24^{\mathrm{a}}$ \\
\hline Anaeroplasmataceae & $0.08 \pm 0.11^{\mathrm{b}}$ & $0.17 \pm 0.17^{\mathrm{ab}}$ & $0.05 \pm 0.05^{\mathrm{b}}$ & $0.30 \pm 0.20^{\mathrm{a}}$ \\
\hline
\end{tabular}

Values are means \pm S.D., $n=10$ /group (AIN, HFD groups) and $n=15$ /group (AIN-AOM, HFD-AOM groups). Means at the same taxon without a common letter differ, $P<.05$. 


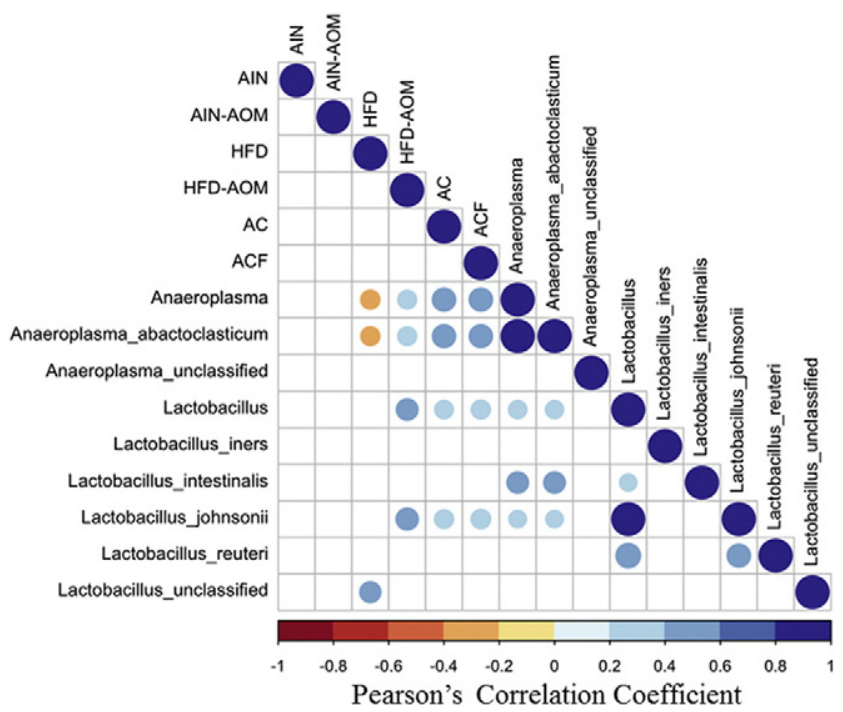

Fig. 7. The effect of HF feeding and AOM treatment on the correlation between AC, ACF and the relative abundance of bacterial Anaeroplasma and Lactobacillus at the genus (all species combined) and species level. Only significant Pearson correlations $(P<.05)$ are shown.

4.3. The combination of HFD consumption and AOM treatment greatly increases colonic AC/ACF formation but does not change liver CYP2E1 enzyme level

Consistent with the inflammatory role of TNF- $\alpha$, IL6, MCP-1, iNOS and Ki67, there were concomitant increases in these inflammation-related proteins and AC/ACF formation in the HFDAOM group when compared with the AIN-AOM group (Figs. 2 and 3; Table 2). This observation suggests a critical role of HFD and inflammation in promoting colonic AC/ACF formation. Likewise, the colonic $\mathrm{AC} / \mathrm{ACF}$ formation could also exacerbate inflammation status, which may become a vicious cycle between colonic AC/ACF formation and chronic inflammatory responses in the HFD-AOM group.

Data suggest that $\mathrm{N}$-nitrosodimethylamine, an AOM isomer, in processed red meat is a major risk factor for colon cancer [62]. In addition, humans are exposed to structurally related hydrazine derivatives found in mushrooms, tobacco, herbicides, rocket fuels and drugs [63]. In contrast to genetically engineered mouse models, AOM induces tumors preferentially in the mouse distal colon with pathological features known to be associated with human sporadic colorectal cancer [64]. Furthermore, a meta-analysis indicated that AOM rodent models were better than genetically engineered models of carcinogenesis in predicting efficacy in humans [64]. As previous data suggest that certain extremely $\mathrm{HF}$ feeding conditions (e.g., 60\% fat $v s 10 \%$ fat as energy source) increase the expression of CYP2E1enzyme which metabolizes AOM in the liver to the bioactive carcinogen [25]. These bioactive metabolites of CYP2E1 are transported to the colon via the bloodstream [37]. However, the contributions of the liver to AOM-induced DNA damage and AC formation in the colon have not been directly determined [65]. In our present study, the moderate HF feeding (e.g., $45 \%$ fat (HFD) vs $16 \%$ fat (AIN) as energy source) did not increase CYP2E1 enzymes but did enhance AC/ACF formation (Fig. 4). Thus, our data support the recent report showing that colonic $\mathrm{AC} / \mathrm{ACF}$ formation is critically dependent on AOM bioactivation by gut bacteria but not hepatic CYP2E1 enzymes [65].

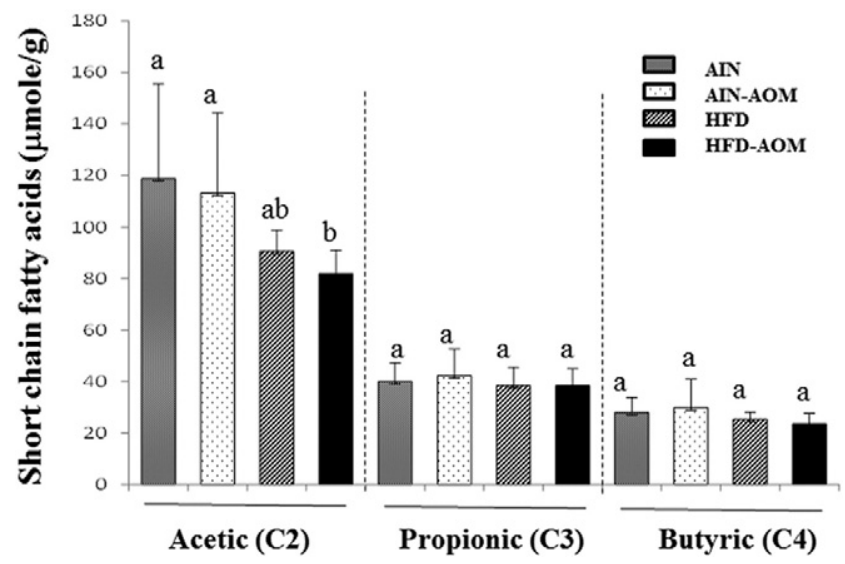

Fig. 8. The effect of HF feeding and AOM treatment on the content of fecal SCFAs. Values are means \pm S.D., $n=10$ /group (AIN, HFD groups) and $n=15$ /group (AIN-AOM, HFDAOM groups). If two bars share at least one letter, then the difference between them is not statistically significant. However, if they do not have a letter in common, then the difference between them is statistically significant, $P<.05$.

4.4. Colonic AC/ACF formation accompanies an increase of opportunistic pathogenic bacteria and LPS but reduces fecal acetic acid content in the HFD-AOM group

Although there are studies on HFD and gut microbiota [66,67], much remains to be determined in the connection of HFD and AC/ACF formation, gut inflammation and microbiota in a mouse model. To gain further insight into the relationship of colon pathophysiology and microbiota, we characterized the HFD-enhanced AC/ACF formation and the respective gut microbiome composition. We found that alpha diversity of the gut microbiome in the AIN and HFD groups did not differ but the HFD-AOM group had a higher diversity which might include pathogenic bacteria when compared to the AIN-AOM group. This observation may reflect the adaptive response that the AIN and HFD groups experience under the different stress conditions (e.g., higher AC number in the HFD-AOM group) due to AOM treatment (Table 3). However, the overall bacterial community structure, beta diversity, was mainly determined by diet (e.g., AIN and HFD) but not AOM treatment or AC formation (Figs. 3, 5).

Similarly, the bacterial abundance at the phylum level in the AIN and HFD groups did not differ. However, the HFD-AOM group increased Proteobacteria but decreased Actinobacteria bacterial abundance when compared to the AIN-AOM group (Figs. 6). The high abundance of Proteobacteria, a microbial signature of dysbiosis, in the HFD-AOM group suggests the unhealthy gut microbiota during AOMinduced AC formation [68,69].

At the genus level, AOM administration increased the abundances of Anaeroplasma bacteria (belonging to Mollicutes class, Tenericutes phylum) and Lactobacillus bacteria, especially in those mice fed an HFD (Figs. 6 and 7; Tables 3 and 4). However, the elevated level of AC/ ACF in the HFD-AOM group did not significantly associate with the abundance of Anaeroplasma and Lactobacillus bacteria when compared to the AIN-AOM group (Figs. 3, 6 and 7; Table 3). This observation suggests that AC/ACF formation (AOM treatment) specifically associates with an increase of Anaeroplasma bacteria, and an HFD may promote this association. The Anaeroplasma bacteria are negative by Gram stain, and they are parasites/opportunistic pathogens which elicit various host immune responses in numerous human diseases including colon cancer $[70,71]$. The important role of LPS in Gramnegative bacteria-induced inflammation has been widely recognized because LPS causes monocytes and phagocytic cells to produce inflammatory cytokines [72,73]. Consistent with these data, there 
was also a high level of plasma LPS (Table 2) in the HFD/AOM group. Therefore, it is conceivable that the increase of Anaeroplasma bacteria and LPS in the HFD/AOM group may, at least, trigger gut inflammation and circulating inflammatory cytokines (Fig. 2; Table 2). On the other hand, Lactobacillus bacteria are generally considered to be probiotic and bile acid tolerant and exhibit beneficial properties relevant to human health (e.g., bile acid deconjugation, anti-infective/anticancer) $[74,75]$. The concomitant increases in the abundance of both Anaeroplasma and Lactobacillus taxa with opposing health impacts (Fig. 7) are likely the result of host-symbiont interactions in which the host requires a tuned response that prevents further host damage (e.g., ACF formation, pathogen infection). This symbiotic relationship might have been established during microbe-host coevolution.

One of the health effects attributed to the production of SCFA is to inhibit pathogenic microorganisms and to maintain the gut barrier function [38]. Although the abundance of certain SCFA-producing bacteria (e.g., Barnesiella, ) [38-41] was lower in the HFD and HFDAOM groups, of the fecal SCFA measured, only acetic acid was lower in the HFD-AOM group compared with the AIN and AIN-AOM groups (Table 3; Fig. 8). This observation was initially counterintuitive given the report that HFD-induced obesity reduces butyrate level in the colon [76]. However, further studies show that there are no consistent conclusions in this regard [76,77]. For example, it did not reduce the concentration of fecal SCFAs in obese mice fed an HFD with 60\% calories from fat [77], while the other study showed that an HFD reduced the butyrate level when (only) pectin was used as fiber source at the initial experimental time point [76]. Therefore, the fiber type (e.g., pectin) and microbial adaptation time point are two critical factors in detecting the reduction of butyrate level in HFD-induced obese mice [76,77]. Similarly, the fecal SCFA concentration did not differ between the AIN and HFD groups, although SCFA-producing bacteria (Bacteroides, Barnesiella, Lachnoclostridium) were in high abundance in the AIN group in our study. This is likely due to the fact that cellulose (an insoluble fiber) was used in our experiments (14 weeks). Our other finding suggests that while the HFD determined the abundance of SCFA-producing bacteria, the combination of HF feeding and AOM treatment was required to decrease fecal acetic acid content. The decrease of acetic acid content in the HFD-AOM group may, at least, be partially related to the dysbiosis because acetic, propionic, butyric acids or their mixture can improve the profile of gut microbiota in the HFD-fed mice [77]. These data also suggest that fecal acetic acid content is more sensitive to the effect of combining dietary fat change and colonic AC formation when compared with other SCFA species.

\subsection{Concluding remarks}

Our data showed that the HFD promoted colonic AC/ACF formation concurrent with an increase of opportunistic pathogenic bacteria and a decrease of SCFA-producing bacteria. Consistent with above observation, AC/ACF formation also associated with an increase of circulating LPS and proinflammatory cytokines, and a decrease of fecal acetic acid. The present study represents a comprehensive report in which we simultaneously determined the impact of the HFD on gut inflammation, colonic ACF formation, gut microbiome composition and their metabolites. Although future human studies are needed when extrapolating these data in clinical application, our newly identified microbiome signatures (e.g., Anaeroplasma) in this study may open new avenues for seeking noninvasive biomarkers.

\section{Acknowledgments}

We greatly appreciate Kay Keehr, James Lindlauf, Bryan Safratowich, Laura Idso and LuAnn Johnson for the technical/statistical support. This work was funded by the US Department of Agriculture, Agricultural Research Service, and Research Project 3062-51000-05000D.

\section{References}

[1] Siegel R, Desantis C, Jemal A. Colorectal cancer statistics. CA Cancer J Clin 2014;64: 104-17.

[2] Zeng H, Lazarova DL. Obesity-related colon cancer: dietary factors and their mechanisms of anticancer action. Clin Exp Pharmacol Physiol 2012;39:161-7.

[3] Calle EE, Kaaks R. Overweight, obesity and cancer: epidemiological evidence and proposed mechanisms. Nat Rev Cancer 2004;4:579-91.

[4] Hou JK, Abraham B, El-Serag H. Dietary intake and risk of developing inflammatory bowel disease: a systematic review of the literature. Am J Gastroenterol 2011;106:563-73.

[5] Giovannucci E, Goldin B. The role of fat, fatty acids, and total energy intake in the etiology of human colon cancer. Am J Clin Nutr 1997;66(6 Suppl):1564S-71S.

[6] Laiyemo AO. The risk of colonic adenomas and colonic cancer in obesity. Best Pract Res Clin Gastroenterol 2014;28:655-63.

[7] O'Neill AM, Burrington CM, Gillaspie EA, Lynch DT, Horsman MJ, Greene MW. High-fat western diet-induced obesity contributes to increased tumor growth in mouse models of human colon cancer. Nutr Res 2016;36:1325-34.

[8] Tahergorabi Z, Khazaei M, Moodi M, Chamani E. From obesity to cancer: a review on proposed mechanisms. Cell Biochem Funct 2016;34:533-45.

[9] van Kruijsdijk RC, van der Wall E, Visseren FL. Obesity and cancer: the role of dysfunctional adipose tissue. Cancer Epidemiol Biomark Prev 2009;18:2569-78.

[10] Versini M, Jeandel PY, Rosenthal E, Shoenfeld Y. Obesity in autoimmune diseases: not a passive bystander. Autoimmun Rev 2014;13:981-1000.

[11] Zackular JP, Baxter NT, Iverson KD, Sadler WD, Petrosino JF, Chen GY, et al. The gut microbiome modulates colon tumorigenesis. MBio 2013:4:e00692-3.

[12] McCoy AN, Araújo-Pérez F, Azcárate-Peril A, Yeh JJ, Sandler RS, Keku TO. Fusobacterium is associated with colorectal adenomas. PLoS One 2013;8:e53653.

[13] Shen XJ, Rawls JF, Randall T, Burcal L, Mpande CN, Jenkins N, et al. Molecular characterization of mucosal adherent bacteria and associations with colorectal adenomas. Gut Microbes 2010;1:138-47.

[14] Chen HM, Yu YN, Wang JL, Lin YW, Kong X, Yang CQ, et al. Decreased dietary fiber intake and structural alteration of gut microbiota in patients with advanced colorectal adenoma. Am J Clin Nutr 2013;97:1044-52.

[15] Sears CL, Islam S, Saha A, Arjumand M, Alam NH, Faruque AS, et al. Association of enterotoxigenic Bacteroides fragilis infection with inflammatory diarrhea. Clin Infect Dis 2008:47:797-803.

[16] Littman DR, Pamer EG. Role of the commensal microbiota in normal and pathogenic host immune responses. Cell Host Microbe 2011;10:311-23.

[17] Kamada N, Seo SU, Chen GY, Núñez G. Role of the gut microbiota in immunity and inflammatory disease. Nat Rev Immunol 2013;13:321-35.

[18] Keerthivasan S, Aghajani K, Dose M, Molinero L, Khan MW, Venkateswaran V, et al. Beta-catenin promotes colitis and colon cancer through imprinting of proinflammatory properties in T cells. Sci Transl Med 2014;6:225ra28.

[19] Turnbaugh PJ, Ley RE, Mahowald MA, Magrini V, Mardis ER, Gordon JI. An obesityassociated gut microbiome with increased capacity for energy harvest. Nature 2006:444:1027-31.

[20] Cox AJ, West NP, Cripps AW. Obesity, inflammation, and the gut microbiota. Lancet Diabetes Endocrinol 2015;3:207-15.

[21] Thorburn AN, Macia L, Mackay CR. Diet, metabolites, and "western-lifestyle" inflammatory diseases. Immunity 2014;40:833-42.

[22] Reeves PG, Nielsen FH, Fahey Jr GC. AIN-93 purified diets for laboratory rodents: final report of the American Institute of Nutrition ad hoc writing committee on the reformulation of the AIN-76A rodent diet. J Nutr 1993;123:1939-51.

[23] Sundaram S, Yan L. Time-restricted feeding reduces adiposity in mice fed a highfat diet. Nutr Res 2016;36:603-11.

[24] Sundaram S, Yan L. Dietary energy restriction reduces high-fat diet-enhanced metastasis of Lewis lung carcinoma in mice. Oncotarget 2016;7:65669-75.

[25] Padidar S, Farquharson AJ, Williams LM, Kearney R, Arthur JR, Drew JE. High-fat diet alters gene expression in the liver and colon: links to increased development of aberrant crypt foci. Dig Dis Sci 2012;57:1866-74.

[26] Bird RP. Observation and quantification of aberrant crypts in the murine colon treated with a colon carcinogen: preliminary findings. Cancer Lett 1987;37: 147-51.

[27] Panchal SK, Poudyal H, Waanders J, Brown L. Coffee extract attenuates changes in cardiovascular and hepatic structure and function without decreasing obesity in high-carbohydrate, high-fat diet-fed male rats. J Nutr 2012;142:690-7.

[28] McCullough AJ. The clinical features, diagnosis and natural history of nonalcoholic fatty liver disease. Clin Liver Dis 2004;8:521-33.

[29] Zeng H, Wu M. The inhibitory efficacy of methylseleninic acid against colon cancer xenografts in C57BL/6 mice. Nutr Cancer 2015;67:831-8.

[30] Dowd SE, Callaway TR, Wolcott RD, Sun Y, McKeehan T, Hagevoort RG, et al. Evaluation of the bacterial diversity in the feces of cattle using 16S rDNA bacterial tag-encoded FLX amplicon pyrosequencing (bTEFAP). BMC Microbiol 2008;8:125.

[31] Zhao G, Nyman M, Jönsson JA. Rapid determination of short-chain fatty acids in colonic contents and faeces of humans and rats by acidified water-extraction and direct-injection gas chromatography. Biomed Chromatogr 2006;20:674-82. 
[32] Ishaq SL, Wright AD. High-throughput DNA sequencing of the ruminal bacteria from moose (Alces alces) in Vermont, Alaska, and Norway. Microb Ecol 2014;68: 185-95.

[33] Schloss PD, Westcott SL, Ryabin T, Hall JR, Hartmann M, Hollister EB, et al. Introducing mothur: open-source, platform-independent, community-supported software for describing and comparing microbial communities. Appl Environ Microbiol 2009;75:7537-41.

[34] Swanson KS, Dowd SE, Suchodolski JS, Middelbos IS, Vester BM, Barry KA, et al. Phylogenetic and gene-centric metagenomics of the canine intestinal microbiome reveals similarities with humans and mice. ISME J 2011;5:639-49.

[35] Edgar RC. Search and clustering orders of magnitude faster than BLAST. Bioinformatics 2010;26:2460-1.

[36] Eren AM, Zozaya M, Taylor CM, Dowd SE, Martin DH, Ferris MJ. Exploring the diversity of Gardnerella vaginalis in the genitourinary tract microbiota of monogamous couples through subtle nucleotide variation. PLoS One 2011;6:e26732.

[37] Rosenberg DW, Giardina C, Tanaka T. Mouse models for the study of colon carcinogenesis. Carcinogenesis 2009;30:183-96.

[38] Ríos-Covián D, Ruas-Madiedo P, Margolles A, Gueimonde M, de Los Reyes-Gavilán CG, Salazar N. Intestinal short chain fatty acids and their link with diet and human health. Front Microbiol 2016;7:185.

[39] Zhao Y, Wu J, Li JV, Zhou NY, Tang H, Wang Y. Gut microbiota composition modifies fecal metabolic profiles in mice. J Proteome Res 2013;12:2987-99.

[40] Woting A, Blaut M. The intestinal microbiota in metabolic disease. Nutrients 2016; $8: 202$.

[41] Cerisy T, Souterre T, Torres-Romero I, Boutard M, Dubois I, Patrouix J, et al, Evolution of a biomass-fermenting bacterium to resist lignin phenolics. Appl Environ Microbiol 2017;83: pii: e00289-17.

[42] Smith BK, Andrews PK, West DB. Macronutrient diet selection in thirteen mouse strains. Am J Physiol Regul Integr Comp Physiol 2000;278:R797-05.

[43] Comuzzie AG, Allison DB. The search for human obesity genes. Science 1998;280: 1374-7.

[44] Hatori M, Vollmers C, Zarrinpar A, DiTacchio L, Bushong EA, Gill S, et al. Timerestricted feeding without reducing caloric intake prevents metabolic diseases in mice fed a high-fat diet. Cell Metab 2012;15:848-60.

[45] Potter GD, Cade JE, Grant PJ, Hardie LJ. Nutrition and the circadian system. Br J Nutr 2016;116:434-42.

[46] Bäckhed F, Ding H, Wang T, Hooper LV, Koh GY, Nagy A, et al. The gut microbiota as an environmental factor that regulates fat storage. Proc Natl Acad Sci U S A 2004; 101:15718-23.

[47] Bäckhed F, Manchester JK, Semenkovich CF, Gordon JI. Mechanisms underlying the resistance to diet-induced obesity in germ-free mice. Proc Natl Acad Sci U S A 2007; 104:979-84

[48] Guzik TJ, Mangalat D, Korbut R. Adipocytokines - novel link between inflammation and vascular function? J Physiol Pharmacol 2006;57:505-28.

[49] Fantuzzi G. Adipose tissue, adipokines, and inflammation. J Allergy Clin Immunol 2005;115:911-9.

[50] Deshmane SL, Kremlev S, Amini S, Sawaya BE. Monocyte chemoattractant protein1 (MCP-1): an overview. J Interf Cytokine Res 2009;29:313-26.

[51] Nagashima R, Maeda K, Imai Y, Takahashi T. Lamina propria macrophages in the human gastrointestinal mucosa: their distribution, immunohistological phenotype, and function. J Histochem Cytochem 1996;44:721-31.

[52] Rugtveit J, Brandtzaeg P, Halstensen TS, Fausa O, Scott H. Increased macrophage subset in inflammatory bowel disease: apparent recruitment from peripheral blood monocytes. Gut 1994;35:669-74.

[53] Svec J, Musílková J, Bryndová J, Jirásek T, Mandys V, Kment M, et al. Enhanced expression of proproliferative and antiapoptotic genes in ulcerative colitisassociated neoplasia. Inflamm Bowel Dis 2010;16:1127-37.

[54] Hiraku Y, Kawanishi S, Ichinose T, Murata M. The role of iNOS-mediated DNA damage in infection- and asbestos-induced carcinogenesis. Ann N Y Acad Sci 2010;1203:15-22.

[55] MacDonald TT. Epithelial proliferation in response to gastrointestinal inflammation. Ann N Y Acad Sci 1992;664:202-9.

[56] Stromar IK, Jakic-Razumovic J. The value of immunohistochemical determination of topoisomerase II $\alpha$ and Ki67 as markers of cell proliferation and malignant transformation in colonic mucosa. Appl Immunohistochem Mol Morphol 2014; 22:524-9.

[57] Randall-Demllo S, Fernando R, Brain T, Sohal SS, Cook AL, Guven N, et al. Characterisation of colonic dysplasia-like epithelial atypia in murine colitis. World J Gastroenterol 2016;22:8334-48.

[58] Jeppsson S, Srinivasan S, Chandrasekharan B. Neuropeptide Y (NPY) promotes inflammation-induced tumorigenesis by enhancing epithelial cell proliferation. Am J Physiol Gastrointest Liver Physiol 2017;312:G103-11.

[59] Zeng H, Ishaq SL, Zhao FQ, Wright AD. Colonic inflammation accompanies an increase of ß-catenin signaling and Lachnospiraceae/Streptococcaceae bacteria in the hind gut of high-fat diet-fed mice. J Nutr Biochem 2016;35:30-6.

[60] DeClercq V, McMurray DN, Chapkin RS. Obesity promotes colonic stem cell expansion during cancer initiation. Cancer Lett 2015;369:336-43.

[61] Hou TY, Davidson LA, Kim E, Fan YY, Fuentes NR, Triff K, et al. Nutrient-gene interaction in colon cancer, from the membrane to cellular physiology. Annu Rev Nutr 2016;36:543-70.

[62] Kim S, Guo J, O'Sullivan MG, Gallaher DD, Turesky RJ. Comparative DNA adduct formation and induction of colonic aberrant crypt foci in mice exposed to 2amino-9H-pyrido[2,3-b]indole, 2-amino-3,4-dimethylimidazo[4,5-f]quinoline, and azoxymethane. Environ Mol Mutagen 2016;57:125-36.

[63] Gamberini M, Cidade MR, Valotta LA, Armelin MC, Leite LC. Contribution of hydrazines-derived alkyl radicals to cytotoxicity and transformation induced in normal c-myc-overexpressing mouse fibroblasts. Carcinogenesis 1998;19: 147-55.

[64] Corpet DE, Pierre F. How good are rodent models of carcinogenesis in predicting efficacy in humans? A systematic review and meta-analysis of colon chemoprevention in rats, mice and men. Eur J Cancer 2005;41:1911-22.

[65] Megaraj V, Ding X, Fang C, Kovalchuk N, Zhu Y, Zhang QY. Role of hepatic and intestinal p450 enzymes in the metabolic activation of the colon carcinogen azoxymethane in mice. Chem Res Toxicol 2014;27:656-62.

[66] Murtaza N, Baboota RK, Jagtap S, Singh DP, Khare P, Sarma SM, et al. Finger millet bran supplementation alleviates obesity-induced oxidative stress, inflammation and gut microbial derangements in high-fat diet-fed mice. Br J Nutr 2014;112: 1447-58.

[67] Daniel H, Moghaddas Gholami A, Berry D, Desmarchelier C, Hahne H, Loh G, et al. High-fat diet alters gut microbiota physiology in mice. ISME J 2014;8:295-308.

[68] Shin NR, Whon TW, Bae JW. Proteobacteria: microbial signature of dysbiosis in gut microbiota. Trends Biotechnol 2015;33:496-503.

[69] Bradley PH, Pollard KS. Proteobacteria explain significant functional variability in the human gut microbiome. Microbiome 2017:5:36

[70] Xu Y, Li H, Chen W, Yao X, Xing Y, Wang X, et al. Mycoplasma hyorhinis activates the NLRP3 inflammasome and promotes migration and invasion of gastric cancer cells. PLoS One 2013;8:e77955.

[71] Yang C, Chalasani G, Ng YH, Robbins PD. Exosomes released from mycoplasma infected tumor cells activate inhibitory B cells. PLoS One 2012;7:e36138.

[72] Zou J, Guo P, Lv N, Huang D. Lipopolysaccharide-induced tumor necrosis factor- $\alpha$ factor enhances inflammation and is associated with cancer (review). Mol Med Rep 2015; 12:6399-404

[73] Sun Y, Shang D. Inhibitory effects of antimicrobial peptides on lipopolysaccharideinduced inflammation. Mediat Inflamm 2015;2015:167572.

[74] Liévin-Le Moal V, Servin AL. Anti-infective activities of lactobacillus strains in the human intestinal microbiota: from probiotics to gastrointestinal anti-infectious biotherapeutic agents. Clin Microbiol Rev 2014;27:167-99.

[75] Spinler JK, Sontakke A, Hollister EB, Venable SF, Oh PL, Balderas MA, et al. From prediction to function using evolutionary genomics: human-specific ecotypes of Lactobacillus reuteri have diverse probiotic functions. Genome Biol Evol 2014;6 1772-89.

[76] Jakobsdottir G, Xu J, Molin G, Ahrne S, Nyman M. High-fat diet reduces the formation of butyrate, but increases succinate, inflammation, liver fat and cholesterol in rats, while dietary fibre counteracts these effects. PLoS One 2013; 8:e80476.

[77] Lu Y, Fan C, Li P, Lu Y, Chang X, Qi K. Short chain fatty acids prevent high-fat-dietinduced obesity in mice by regulating $G$ protein-coupled receptors and gut microbiota. Sci Rep 2016:6:37589. 